\title{
EFFECT OF CALCIUM HYDROXIDE ON THE MICROSTRUCTURE AND PERFORMANCE OF SUPER SULFATED CEMENT
}

\author{
\#JIAN-WEI ZHOU*, BAO-YING YU*, YA-NING KONG*, WEN YANG*, BAO-JUN CHENG*, JING WU** \\ *China West Construction Academy of Building Materials, Chengdu, China, 610094 \\ **School of Materials Science and Engineering, Wuhan Textile University, Wuhan 400045, China \\ "E-mail: jianzhucat@163.com
}

Submitted November 12, 2021; accepted January 8, 2022

\begin{abstract}
Keywords: Calcium hydroxide, Super sulfated cement, Microstructure, Hydration products
The effects of a 0, $0.2 \mathrm{wt} . \%, 0.6 \mathrm{wt} . \%, 1.0 \mathrm{wt} . \%, 1.4 \mathrm{wt} . \%$ and $1.8 \mathrm{wt} . \%$ calcium hydroxide content on the microstructure and performance of super sulfated cement (SSC) were investigated. The results showed that the setting time of SSC could be reduced by the calcium hydroxide content to less than 7 hours. The variation in the setting time did not affect the working performance of the SSC. The mechanical properties of the SSC can be consistently and gradually enhanced by calcium hydroxide. The SSC, with a 3-day compressive strength of $22.3 \mathrm{MPa}$ and a 28-day compressive strength of 45.1 MPa, was prepared by introducing $0.6 \mathrm{wt}$. \% calcium hydroxide into the system. A microanalysis revealed that the reaction mechanism of the SSC was influenced by the calcium hydroxide, which led to changes in the hydration products as well as the structure. In particular, large amounts of ettringite (AFt) were prompted in the SSC prepared with the raw materials at the early stage. The change in the structure of the hydration products led to a significant improvement in the mechanical properties.
\end{abstract}

\section{INTRODUCTION}

Super sulfated cement (SSC) is a kind of green cementitious material with slag $(75-85 \%)$ as the main constituent, gypsum $(10-20 \%)$ as the sulfate activator and clinker or lime as the alkaline activator (1 - $5 \%$ ), which produces a lower $\mathrm{CO}_{2}$ footprint during its production $[1,2]$. Therefore, SSC is considered as an alternative to Portland cement [3]. The hydration process of SSC is demonstrated in Equation $1[4,5]$.

$$
\mathrm{C}_{5} \mathrm{~S}_{3} \mathrm{~A}+\mathrm{CH}+3 \mathrm{C} \overline{\mathrm{S}}+34 \mathrm{H} \rightarrow \mathrm{C}_{6} \mathrm{AS}_{3} \mathrm{H}_{32}+3 \mathrm{CSH}
$$

The small proportion of alkaline activator occurs initially encountering water $(\mathrm{H})$, providing calcium hydroxide $(\mathrm{CH})$, which promotes the dissolution of $\mathrm{Ca}^{2+}, \mathrm{Al}^{3+}$, $\left[\mathrm{SiO}_{4}\right]^{4-}$ in the slag. The reactive aluminium and silicon dissolved from the slag react with the calcium sulfate forming ettringite $\left(\mathrm{AFt}, 3 \mathrm{CaO} \cdot \mathrm{Al}_{2} \mathrm{O}_{3} \cdot 3 \mathrm{CaSO}_{4} \cdot 32 \mathrm{H}_{2} \mathrm{O}\right.$, $\left.\mathrm{C}_{6} \mathrm{~A} \overline{\mathrm{S}}{ }_{3} \mathrm{H}_{32}\right)$ and calcium silicate hydrate $(\mathrm{C}-\mathrm{S}-\mathrm{H}$, $\mathrm{CaO} \cdot \mathrm{SiO}_{2} \cdot \mathrm{H}_{2} \mathrm{O}$, with no specific stoichiometry).

Compared with ordinary Portland cement and Portland blast furnace-slag cement, SSC's hydration products are mainly AFt and a C-S-H gel. SSC has a lower heat release and a slow hydration rate. Thus, it has obvious advantages in large volume concrete projects [6, 7]. For example, China Construction Commercial Concrete Co. Ltd. used SSC concrete with a design strength of C40 to pave the road around its concrete plants in 2014. All the performance aspects met the requirements of road construction, and the engineering application effect is excellent [8]. Moreover, SSC, owning greatly to its excellent resistance to sulfate attack, has been applied in high sulfate environments to provide durability that exceeds expectations for structures [9]. Grounds [10] studied the resistance of SSC to erosion by strong sulfate solutions at $25{ }^{\circ} \mathrm{C}$ and $95{ }^{\circ} \mathrm{C}$ for 28 days and 180 days under maintenance conditions. The results showed that SSC was resistant to sulfate erosion with or without the decomposition of calcium alumina. Although SSC has many of these excellent properties, its promotion is still immature. The main reasons are attributed to the long setting time [1,2], slow early strength development $[11,12]$, and poor carbonation resistance $[3,13]$ of the SSC. The setting time of SSC is prolonged by $2-3 \mathrm{~h}$, compared with traditional Portland cement. Moreover, changes in the curing conditions are very likely to affect its volumetric stability due to the higher content of ettringite in the system $[1,11]$. However, ettringite could experimentally lose its crystallinity at $60-70^{\circ} \mathrm{C}$, which has been reported by Chen et al. [14,15].

The early mechanical properties of SSC can be enhanced by the slag with a higher content of alumina oxide. Kondo et al. [16] reported that $22 \%$ of the slag was hydrated when the active alumina oxide in the system reached $18.5 \%$. As a result, the prepared SSC achieved excellent mechanical properties at the early stage. Masoudi et al. [17] considered that a slag with alumina oxide content greater than $13 \%$ is suitable for the SSC preparation, so that SSC can reach a high early strength. However, the alumina oxide content in the slag 
is easily affected by the production process and the raw materials. The introduction of high purity active alumina into the system tends to cause higher costs, which is not in line with the concept of green and sustainable development.

Even if a suitable slag is used as raw material, the carbonation resistance of SSC is still poor. According to Castellote et al. [18], C-S-H shows a higher rate of carbonation followed by calcarenite. Due to the low or zero content of calcium hydroxide in the SSC matrix, the $\mathrm{C}-\mathrm{S}-\mathrm{H}$ and calcarenite formed during hydration are susceptible to carbonation processes. This contributes to the high carbonation rate of the SSC. Sabrina R. Pinto et al. [19] confirmed an increase in porosity of carbonated SSC concrete specimens by analysing the cross-sectional morphology of the concrete after carbonation, which resulted in a decrease in the compressive strength of the concrete.

The alkali activator is one of the key factors affecting the performance of SSC. Zhou et al. [3] investigated the effects of alkali activators (lactates and sodium hydroxyl) on the microstructure and properties of SSC concrete. It was found that the addition of lactate affects the hydration of the slag, resulting in more calcium alumina and a denser microstructure of the persulfate cement concrete, while sodium hydroxyl failed to improve the microstructure of the SSC concrete. However, Gijbels K. et al. [20] found that the highest porosity and strength of the specimens were observed without the addition of $\mathrm{NaOH}$, and when the mass molar concentration of $\mathrm{NaOH}$ was $2 \mathrm{~mol}$ and higher, the ettringite disappeared and was replaced by the monosulfate phase and amorphous aluminium hydroxide. According to Lei et al. [21], calcium hydroxide can promote the alkali-silica reaction in alkali-activated gelling materials, where the presence of calcium ions contributes to the formation of a hydration gel.

As mentioned above, the selection of alkali activators affects the performance of the SSC. Suitable alkali activators can significantly improve the performance of SSCs, while the activators used are concentrated in lime, sodium hydroxide, and alkaline salts, etc. Calcium hydroxide not only acts as an alkali activator, but also provides calcium ions. However, the effect of calcium hydroxide on the SSC is rarely reported, compared with other alkali activators. It is necessary to explore the mechanism of calcium hydroxide on the SSC. Therefore, the effects of calcium hydroxide on the setting time, fluidity, strength, hydration products and microstructure of an SSC were investigated in the paper.

\section{MATERIALS AND METHODOLOGY}

\section{Materials}

The clinker was obtained from Xinjiang China West Construction Group Co., Ltd. The physical properties of the cement clinker are shown in Table 1. The slag, with a physical phase composition of dicalcium silicate, calcium aluminium oxide, calcium oxide (as shown in Figure 1), was obtained from the Xinjiang Bayi Steel Plant. The physical properties of the slag are shown in Table 2. The desulfurization gypsum was obtained from the Xinjiang Manas Power Plant. The calcium hydroxide, with a purity specification of analytical purity and calcium hydroxide content $\geq 98 \%$, was purchased from Chengdu Jinshan Chemical Reagent Co., Ltd. The quartz sand was China ISO standard sand produced by Xiamen Aisiou Standard Sand Co., Ltd. The chemical compositions of the clinker, slag and desulfurization gypsum is shown in Table 3, and the appearance morphology is shown in Figure 1.

Table 2. Physical properties of the slag.

\begin{tabular}{cccc}
\hline $\begin{array}{l}\text { Density } \\
\left(\mathrm{g} \cdot \mathrm{cm}^{-3}\right)\end{array}$ & $\begin{array}{c}\text { Specific surface } \\
\left(\mathrm{m}^{2} \cdot \mathrm{kg}^{-1}\right)\end{array}$ & \multicolumn{2}{c}{ Activity $(\%)$} \\
\cline { 3 - 4 } & 410 & 79 & 28 days \\
\hline 2.9 & 410 & & 87 \\
\hline
\end{tabular}

Table 3. Chemical composition of the different raw materials (wt. \%).

\begin{tabular}{cccc}
\hline $\begin{array}{c}\text { Chemical } \\
\text { composition }\end{array}$ & Clinker & Slag & $\begin{array}{c}\text { Desulfurization } \\
\text { gypsum }\end{array}$ \\
\hline $\mathrm{CaO}$ & 69.19 & 40.39 & 48.75 \\
$\mathrm{SiO}_{2}$ & 25.12 & 35.56 & 4.66 \\
$\mathrm{Al}_{2} \mathrm{O}_{3}$ & 2.11 & 11.55 & 1.27 \\
$\mathrm{MgO}$ & 1.26 & 7.16 & 0.876 \\
$\mathrm{~K}_{2} \mathrm{O}$ & 0.667 & 0.517 & 0.173 \\
$\mathrm{SO}_{3}$ & 0.596 & - & 40.2 \\
$\mathrm{Na}_{2} \mathrm{O}$ & 0.367 & 1.04 & 0.375 \\
$\mathrm{Fe}_{2} \mathrm{O}_{3}$ & 0.232 & 0.398 & 0.527 \\
$\mathrm{P}_{2} \mathrm{O}_{5}$ & 0.145 & - & 0.456 \\
$\mathrm{TiO}_{2}$ & 0.127 & 1.59 & 0.0566 \\
$\mathrm{ZnO}$ & 0.0636 & 0.06 & 0.033 \\
$\mathrm{MnO}$ & 0.06 & 0.13 & 0.0117 \\
$\mathrm{Cl}$ & 0.0526 & - & 1.27 \\
\hline $\mathrm{Others}$ & 0.0298 & 1.605 & 1.3417 \\
\hline & & &
\end{tabular}

Table 1. Physical properties of the clinker.

\begin{tabular}{|c|c|c|c|c|c|c|}
\hline \multirow{3}{*}{$\begin{array}{l}\text { Specific surface } \\
\quad\left(\mathrm{cm}^{2} \cdot \mathrm{g}^{-1}\right)\end{array}$} & \multirow{2}{*}{\multicolumn{2}{|c|}{ Setting time (min) }} & \multicolumn{4}{|c|}{ Mechanical property (MPa) } \\
\hline & & & \multicolumn{2}{|c|}{7 days } & \multicolumn{2}{|c|}{28 days } \\
\hline & Initial & Final & $\begin{array}{l}\text { Flexural } \\
\text { strength }\end{array}$ & $\begin{array}{l}\text { Compressive } \\
\text { strength }\end{array}$ & $\begin{array}{l}\text { Flexural } \\
\text { strength }\end{array}$ & $\begin{array}{c}\text { Compressive } \\
\text { strength }\end{array}$ \\
\hline 3480 & 92 & 128 & $6.2 \pm 0.5$ & $30.6 \pm 0.8$ & $8.7 \pm 0.6$ & $52.6 \pm 0.5$ \\
\hline
\end{tabular}




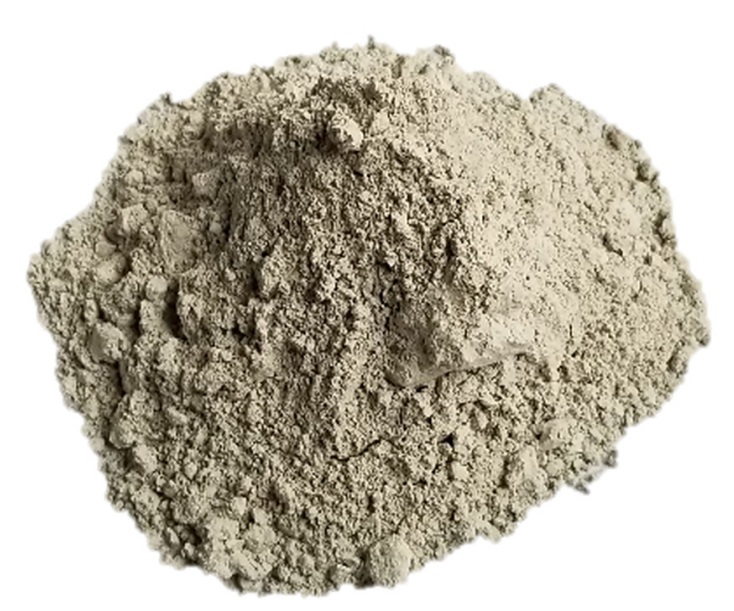

a)

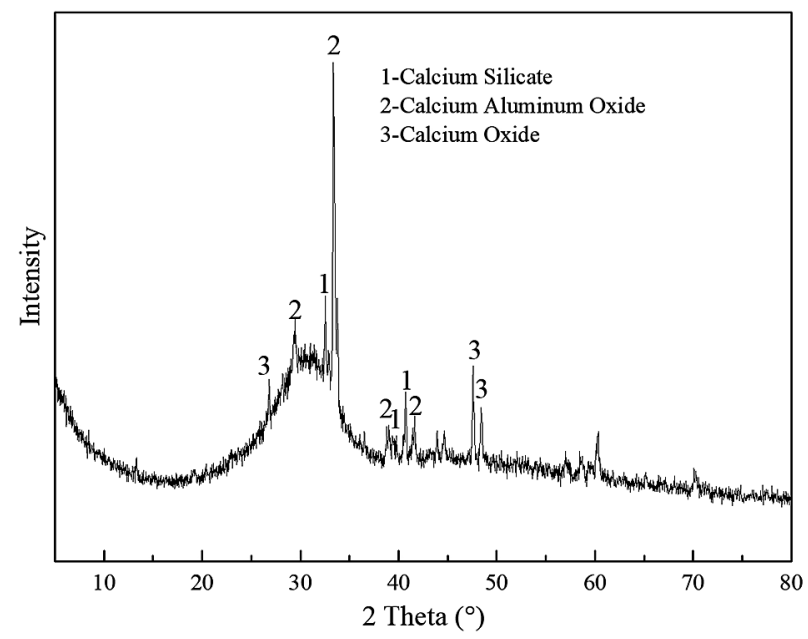

b)

Figure 1. Appearance and phase compositions of the slag.

\section{Methodology}

\section{Preparation of the specimens}

The components of the formulated SSC were as follows: 82 wt. $\%$ mineral powder, 15 wt. $\%$ desulfurization gypsum, and 3 wt. \% cement clinker, where the desulfurization gypsum was dried at $45^{\circ} \mathrm{C}$ for $24 \mathrm{~h}$. A $5 \mathrm{~kg}$ mixture weighed according to the above mix proportion, was homogenised in an SM500 blender with a speed of $48 \mathrm{rpm}$ for $5 \mathrm{~min}$. This approach resulted in a more uniform mix for each component. Calcium hydroxide was added into the SSC according to the quality of the cement, and the proportion is shown in Table 4. The SSC mortar was prepared according to the mixing method in GBT17671-1999 "Test Method of Cementitious Mortar Strength (ISO Method)". Hardened or prepared specimens with a size of $40 \times 40 \times 160 \mathrm{~mm}$ were removed from a mould after curing for $24 \mathrm{~h}$ (temperature: $30{ }^{\circ} \mathrm{C}$; humidity: $70 \%$ ). Then, they were cured under standard curing conditions (temperature: $20 \pm 2{ }^{\circ} \mathrm{C}$, humidity: $\geq 95 \%$ ) up to 3,7 and 28 days.
Table 4. Proportioning design of the cement in wt. \%.

\begin{tabular}{cc}
\hline Material ID & Calcium hydroxide \\
\hline $\mathrm{JZ}$ & 0 \\
$\mathrm{SSC} 1$ & 0.2 \\
$\mathrm{SSC} 2$ & 0.6 \\
$\mathrm{SSC} 3$ & 1.0 \\
$\mathrm{SSC} 4$ & 1.4 \\
$\mathrm{SSC} 5$ & 1.8 \\
\hline
\end{tabular}

\section{Method}

The setting time of cement was measured by a Vicat apparatus according to GBT1346-2011 "Test methods for water requirement of normal consistency, setting time and soundness of the Portland cements". The fluidity of the fresh mortar was measured by an NLD 3 apparatus of fluidity of cement mortar according to GB/T24192005 "Test method for fluidity of cement mortar". The compressive and flexural strength of the specimens at a different age were tested by a TYE-300D type cementitious sand flexural and compressive testing machine according to GBT17671-1999 "Method of testing cements-determination of strength (ISO Method)". The loading rate of the flexural strength is $0.05 \mathrm{kN} \cdot \mathrm{S}^{-1}$, and the loading rate of the compressive strength is $2.4 \mathrm{kN} \cdot \mathrm{S}^{-1}$. The small parts of the hardened paste corresponding to the specimens without sand was taken for microscopic testing. These selected small parts were soaked in anhydrous ethanol for $24 \mathrm{~h}$ to terminate the hydration reaction, and then dried at $40{ }^{\circ} \mathrm{C}$ for $48 \mathrm{~h}$. An X-ray diffraction (XRD) test was carried using Brook D8 X-ray diffractometer with a scan speed of $10^{\circ} 2 \theta \cdot \mathrm{min}^{-1}$ from $5^{\circ}$ to $80^{\circ}$. The scanning electron microscopy (SEM) were measured by ZEISS SUPRA 55 Field Emission Scanning Electron Microscope, in order to directly observe the fracture morphology of the specimens. Before testing, the specimens were sprayed with gold in a vacuum environment. Fourier infrared (IR) spectra of the specimens were measured by a Thermo Fisher Fourier infrared spectrometer.

\section{DISCUSSION AND RESULTS}

\section{Setting time of cement}

Figure 3 shows the effect of calcium hydroxide on the setting time of the SSC. It can be seen from Figure 3 that the setting time of the SSC was significantly shortened due to the introduction of calcium hydroxide. The initial setting time of SSC5 is $375 \mathrm{~min}$, and the final setting time is $450 \mathrm{~min}$. Compared with the control group (JZ), the initial setting time of the SSC was shortened by $200 \mathrm{~min}$, and the final setting time was shortened by $270 \mathrm{~min}$. This reveals that the introduction of calcium hydroxide can significantly reduce the setting time of the SSC. Although the setting time is still longer than that of ordinary Portland cement, it is also important for the promotion of SSC. 


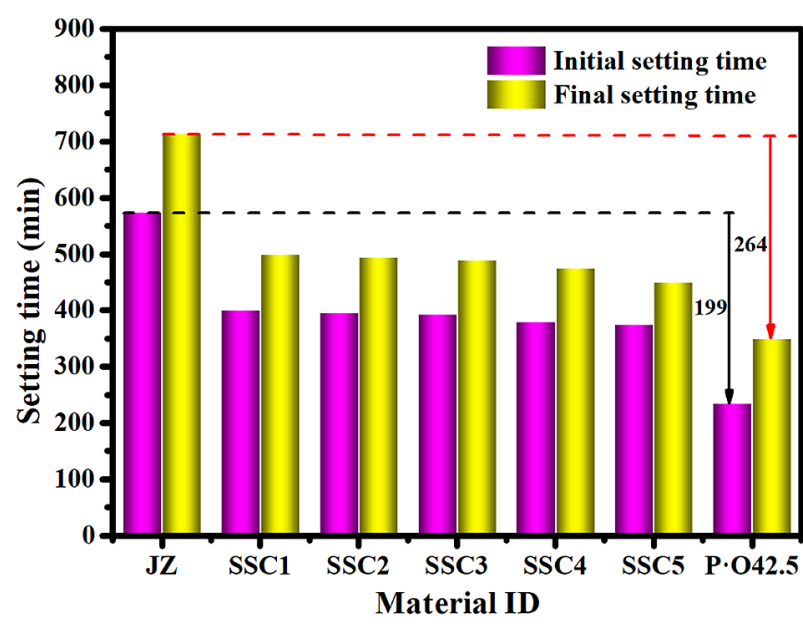

Figure 3. Effect of calcium hydroxide on the setting time of cement.

\section{Fluidity}

Figure 4 reveals the effect of calcium hydroxide on the fluidity of the SSC. The figure shows there is little difference in the workability of the fresh mixture. With an increase in the calcium hydroxide content, the fluidity of the mixtures decreased slightly. The fluidity of the mixtures fluctuated around $200 \mathrm{~mm}$, indicating that the addition of calcium hydroxide had little effect on the working performance of the SSC.
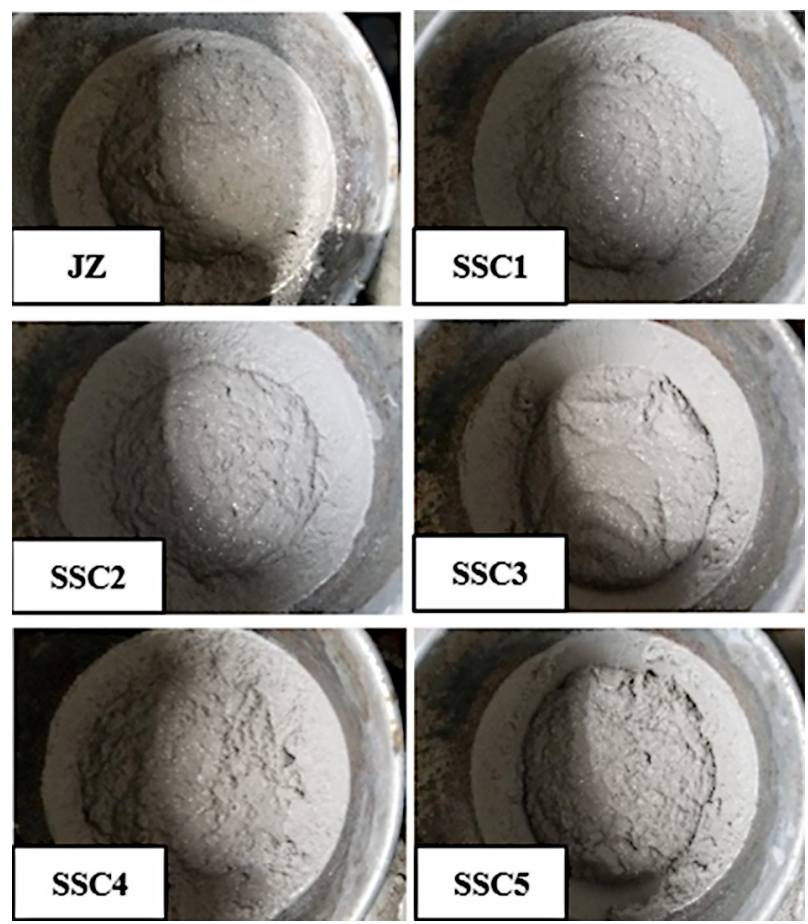

a)
Mechanical properties

Figure 5 shows the effect of the calcium hydroxide on the mechanical properties of the SSC. Although the control group specimen had an integral appearance at 3 days, the strength was too low to record. The compressive strength of the specimens reached 15.6 MPa until 7 days. However, the compressive strengths of SSC2 reached $22.3 \mathrm{MPa}$ at 3 days and $32.2 \mathrm{MPa}$ at 7 days, respectively. The reason for this result is that the lower activity made the early strength of the specimen develop slowly [22]. The introduction of calcium hydroxide further stimulated the activity of the slag, which accelerated the development of the early mechanical properties of the specimens. Thus, the addition of the calcium hydroxide provides high early strength for the SSC. The mechanical properties at an early period of the specimens were promoted with an increase in the calcium hydroxide content except for the content exceeding $0.6 \%$.

The 28-d compressive strength development of the specimens showed a similar trend to that of the earlier period. The compressive strengths of SSC1, SSC2, SSC3, SSC4, and SSC5 were changed than those of the JZ by $36.3 \%, 37.5 \%, 25.0 \%,-2.7 \%$, and $-6.1 \%$ after curing up to $28 \mathrm{~d}$, respectively. The comparative results imply that the addition of calcium hydroxide at a suitable level can significantly improve the compressive strength of the SSC. The suitable content in this paper is 0.6 wt. \%. Compared with the control group, the flexural strength of the specimens was significantly higher after the introduction of the calcium hydroxide. The flexural strength of SSC3 was the highest among all the specimens, which was $51.4 \%$ higher than that of the JZ. Similarly, the flexural strength of the specimens appeared to be decreased when the calcium hydroxide content was too high. The effect of calcium hydroxide on the flexural strength is the same as that of compressive strength.

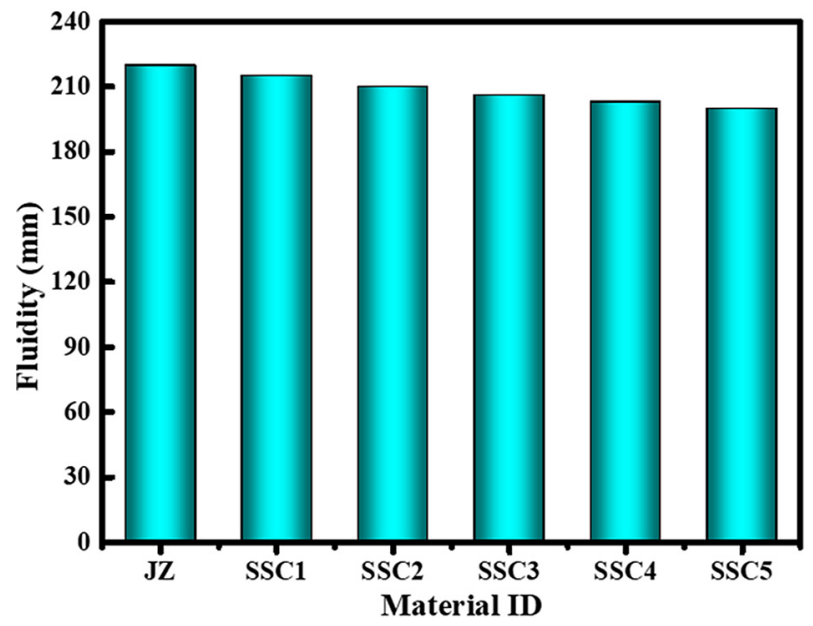

b)

Figure 4. Effect of calcium hydroxide on the fluidity of the super sulfate cement mortar. 


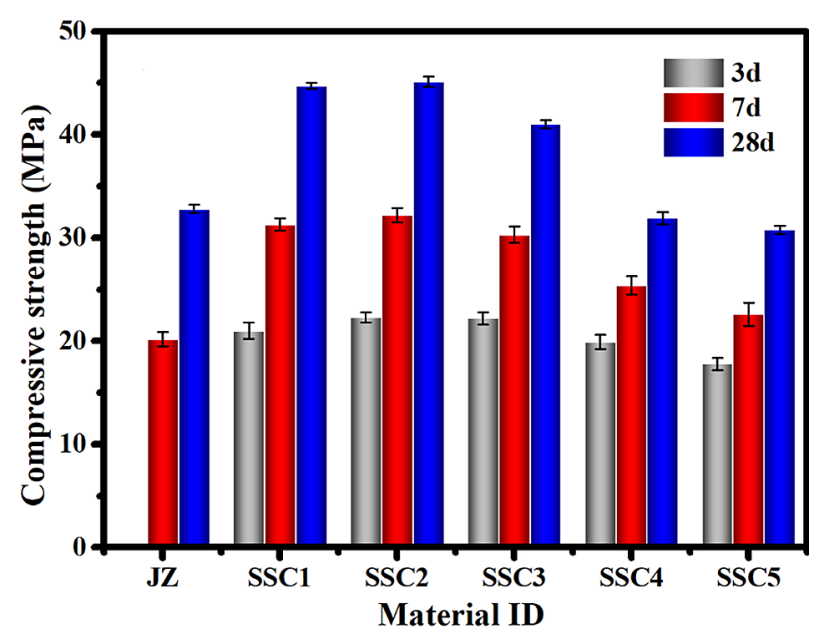

a)

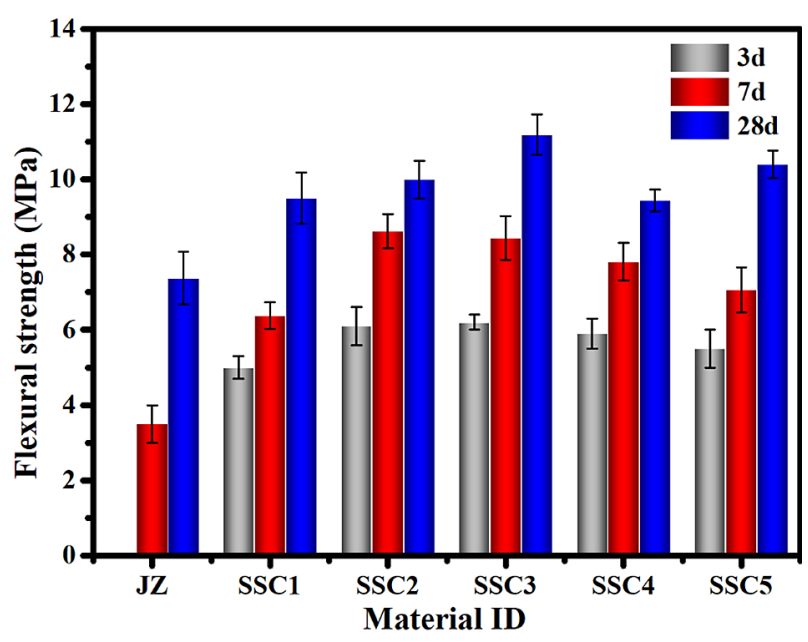

b)

Figure 5. Mechanical properties: a) compressive strength b) flexural strength of the specimens.

Microstructure analysis

\section{Hydration products}

Figure 6 shows the XRD pattern of the JZ, SSC2, and SSC4 specimens curing up to 7 days. From the XRD pattern, each curve contains firm diffraction peaks of calcite, which is due to the carbonation of the hydration products in the tested specimen during the curing. This is the characteristic of SSC that is extremely easy to carbonate. The reaction process is shown in Equation 2 and 3 [1].

$$
\begin{aligned}
& 3 \mathrm{CaO} \cdot \mathrm{Al}_{2} \mathrm{O}_{3} \cdot 3 \mathrm{CaSO}_{4} \cdot 32 \mathrm{H}_{2} \mathrm{O}+3 \mathrm{H}_{2} \mathrm{CO}_{3} \rightarrow \\
& \rightarrow 3 \mathrm{CaCO}_{3}+3 \mathrm{CaSO}_{4}+\mathrm{Al}_{2} \mathrm{O}_{3} \cdot \mathrm{XH}_{2} \mathrm{O}+ \\
& +(35-\mathrm{X}) \mathrm{H}_{2} \mathrm{O} \\
& \mathrm{XCaCO}_{3} \cdot \mathrm{YSiO}_{2} \cdot \mathrm{H}_{2} \mathrm{O}+\mathrm{XH}_{2} \mathrm{CO}_{3} \rightarrow \\
& \rightarrow \mathrm{XCaCO}_{3}+\mathrm{YSiO}_{2}+(\mathrm{X}+1) \mathrm{H}_{2} \mathrm{O}
\end{aligned}
$$

For control group, JZ, the crystalline phase of the hydration products at 7 days is mainly gypsum and a small amount of calcite. The diffraction background of the curve indicates the presence of a large amount of amorphous material, which may be unreacted slag or hydrated product $\mathrm{C}-\mathrm{S}-\mathrm{H}$ gel [23]. However, the diffraction peak of ettringite, a common hydration product in SSC [24], was not detected in the control group. Meanwhile, the control group had higher mechanical properties at 7 days, indicating that the early strength of control group is mainly provided by the $\mathrm{C}-\mathrm{S}-\mathrm{H}$ gel. It also explains the low 3 days strength in the mechanical properties test, where the effective strength could not be recorded. The difference in the hydration products at the early period with conventional SSC is attributed to the fact that the physical phase composition of the slag with low reactivity is mainly dicalcium silicate. Compared with the control group, the early hydration products, at the specimen's early period, changed significantly with the introduction of calcium hydroxide. The presence of ettringite was observed and the corresponding diffraction peaks are $2 \theta=9.1^{\circ} 15.8^{\circ}, 17.8^{\circ}, 19.0^{\circ}, 22.9^{\circ}, 25.6^{\circ}, 32.3^{\circ}, 35.0^{\circ}$. The hydration process of ettringite is shown in Equation 4 [25].

$$
\begin{aligned}
& \mathrm{Al}_{2} \mathrm{O}_{3}+3 \mathrm{Ca}(\mathrm{OH})_{2}+30 \mathrm{CaSO}_{4} \cdot 2 \mathrm{H}_{2} \mathrm{O} \rightarrow \\
& \rightarrow 3 \mathrm{CaO} \cdot \mathrm{Al}_{2} \mathrm{O}_{3} \cdot 3 \mathrm{CaSO}_{4} \cdot 32 \mathrm{H}_{2} \mathrm{O}
\end{aligned}
$$

The main crystal phase is composed of ettringite, gypsum, and a small amount of calcite. The early strength of SSC was provided by the $\mathrm{C}-\mathrm{S}-\mathrm{H}$ gel and ettringite, which promoted the development of the mechanical pro-perties at the early period, as mentioned in chapter Mechamical properties.

Figure 6 shows the XRD pattern of the JZ, SSC2, and SSC4 specimens curing up to 28 days. The presence of ettringite was observed in the control group and the corresponding diffraction peaks are $2 \theta=9.1^{\circ}, 23.1^{\circ}$, $32.5^{\circ}, 34.5^{\circ}$. However, there are only a few low-intensity ettringite diffraction peaks. The intensity of the ettringite diffraction peaks increased significantly with the addition of calcium hydroxide, indicating that the calcium hydroxide in the presence of gypsum promotes the formation of ettringite in the SSC.

$$
\text { E-ettringite, G-gypsum, C-calcite }
$$

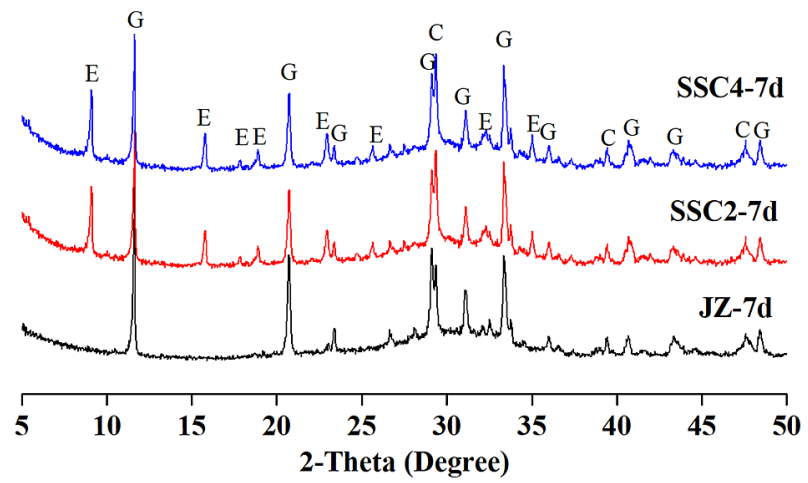

Figure 6. XRD pattern of the JZ, SSC2, and SSC4 specimens curing up to 7 days. 


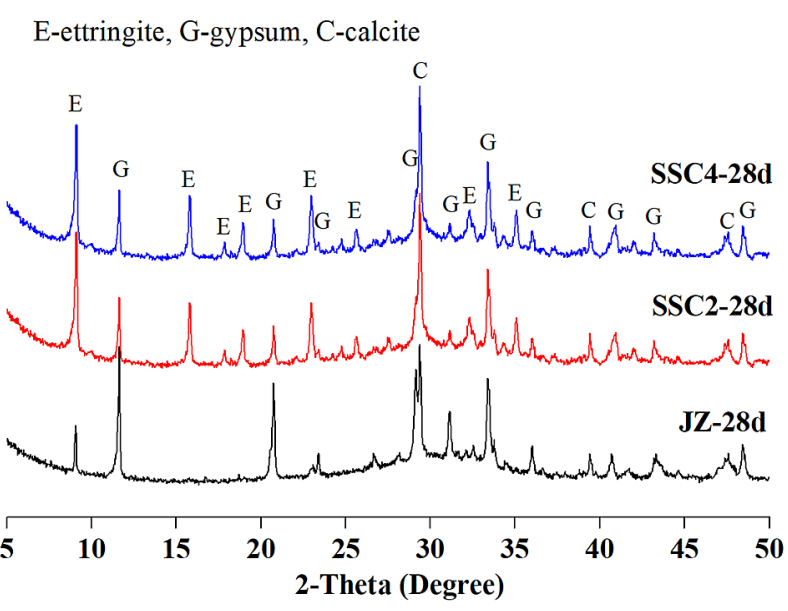

Figure 7. XRD pattern of the JZ, SSC2, and SSC4 specimens curing up to 28 days.

Figure 8 shows the comparison results of the XRD patterns at $5^{\circ}-20^{\circ}$ of the control group curing up to 7 days and 28 days, respectively. As can be seen from figure, the XRD patterns of the control group at both 7 and 28 days days were different at $9.1^{\circ}$. There is no obvious ettringite diffraction peak at 7 days. However, the diffraction peak of the ettringite appeared in the control group curing up to 28 days. In terms of the analysis, the calcium hydroxide played a key role in the early period reaction of the SSC

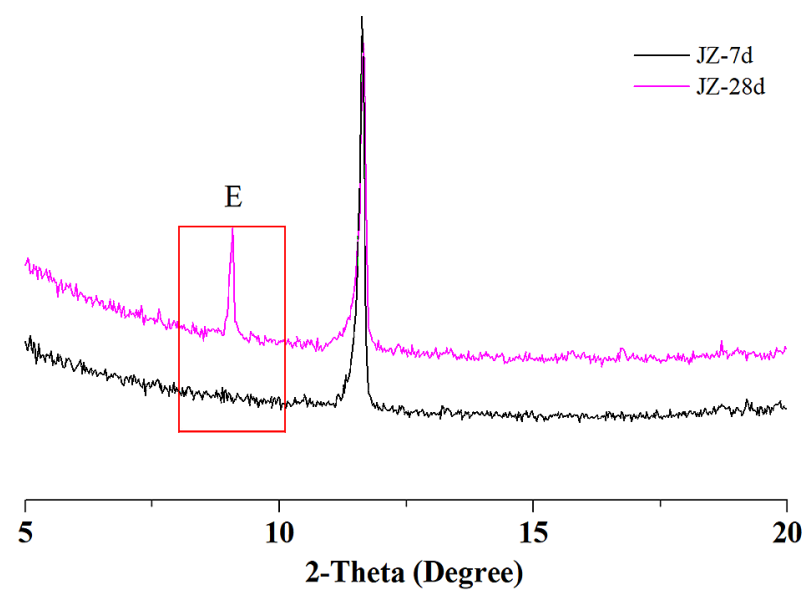

Figure 8 . XRD patterns at $5^{\circ}-20^{\circ}$ of the control group (7 and 28 days).

\section{FT-IR analysis}

Figure 9 shows the FTIR spectra of the specimens hydrated up to 28 days. The variation in the spectrum of the specimens is small, indicating that the hydration products of the tested specimens are relatively similar. All the specimens showed a complex set of peaks around $400 \sim 670 \mathrm{~cm}^{-1}$, which corresponded to the flexural vibra-tion absorption of the $\mathrm{Si}-\mathrm{O}-\mathrm{Si}$ bonds [3]. It may be due to the presence of the unhydrated slag and some impurities [3, 26]. The absorption peaks around $873 \mathrm{~cm}^{-1}$ and $1450 \mathrm{~cm}^{-1}$ are caused by the vibration of the $\mathrm{C}-\mathrm{O}$ bonds in the calcite [27]. As mentioned in chapter Hydration products, the hydration products inevitably came into contact with carbon dioxide in the air during the specimen preparation, forming calcite [27]. This absorption peak shifts to a lower wave number after doping with calcium hydroxide, indicating the lighter carbonation of the calcium hydroxide doped specimens. The absorption peaks around $900 \sim 1000 \mathrm{~cm}^{-1}$ of the $\mathrm{Si}-\mathrm{O}$ Si (Al) bonds are present in all the specimens. The peak at about $998 \mathrm{~cm}^{-1}$ is found in the specimen without the calcium hydroxide. As analysed, the vibration absorption of the $\mathrm{Si}-\mathrm{O}-\mathrm{Si}(\mathrm{Al})$ bond in the system is reduced, which also proves that the hydrated gel content in the product decreased $[26,28]$. The spectra of specimens all have an absorption peak at $1119 \mathrm{~cm}^{-1}$, which corresponds to the contraction vibration of the $\mathrm{S}-\mathrm{O}$ bonds [29]. This is due to the presence of large amounts of $\mathrm{SO}_{4}{ }^{2-}$ in the $\mathrm{SSC}$ system. The absorption peaks around $1620 \mathrm{~cm}^{-1}$ corresponds to the $\mathrm{O}-\mathrm{H}$ vibrations in $[\mathrm{Al}(\mathrm{OH})]^{3-}[3,29]$. This absorption peak shifted to a high wave number after adding calcium hydroxide, indicating that the vibration of $\left[\mathrm{Al}(\mathrm{OH})_{6}\right]_{3}{ }^{-}$is strengthened and the ettringite content in the system increased. The comparison of the high frequency region shows that the absorption peak of the sample after doping with calcium hydroxide shifted from $3405 \mathrm{~cm}^{-1}$ to a high wave number, which corresponded to the contraction vibration of $\mathrm{O}-\mathrm{H}[3,26,28]$.

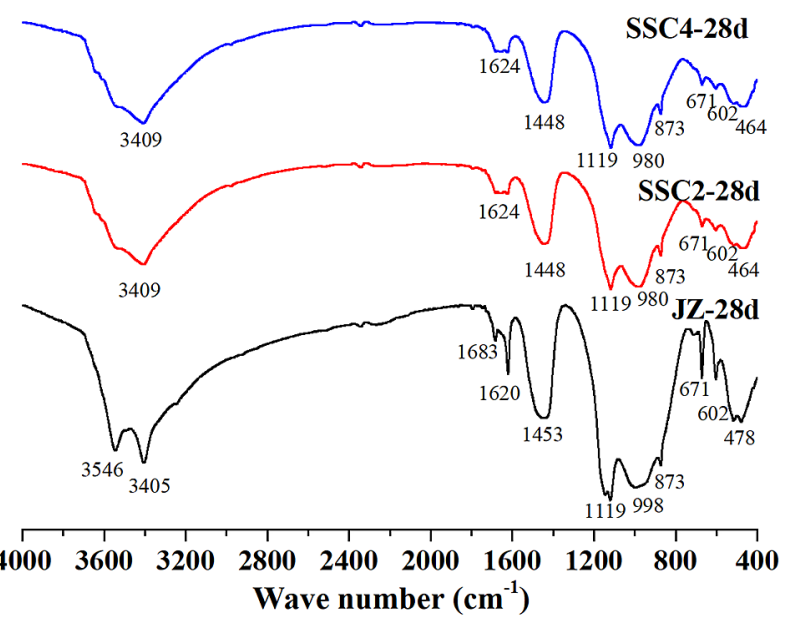

Figure 9. Fourier transform infrared spectrometry of the specimens.

\section{Morphology}

The microscopic morphology of the two types of SSC curing up to 7 days was characterised. The results are shown in Figure 10, where Figure 10a is the control group, JZ, and Figure 10b is the specimen with the addition of calcium hydroxide, SSC2. As shown in the figure, the cross-sectional morphology of the JZ mainly consisted of short bar-loaded crystals as well as some amorphous products. Combined with the energy 
dispersive spectroscopy corresponding to the area in Figure 10a 1 and 2, gypsum and $\mathrm{C}-\mathrm{S}-\mathrm{H}$ gel are the products corresponding to the elemental composition, respectively. The dihydrate gypsum was covered by $\mathrm{C}-\mathrm{S}-\mathrm{H}$ gel and the densities of structures are low. In contrast, a large amount of ettringite was present in the cross-sectional morphology of the SSC2. Ettringite with a larger ratio of the length to the diameter and the $\mathrm{C}-\mathrm{S}-\mathrm{H}$ gel interlaced with each other made the structure comparatively dense, which enhanced the energy absorption ability of the
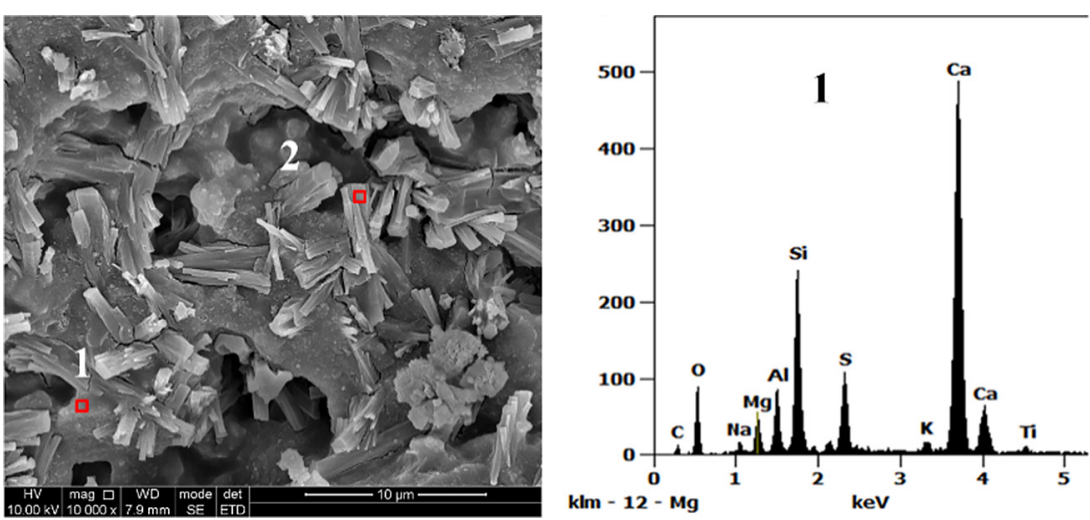

a)
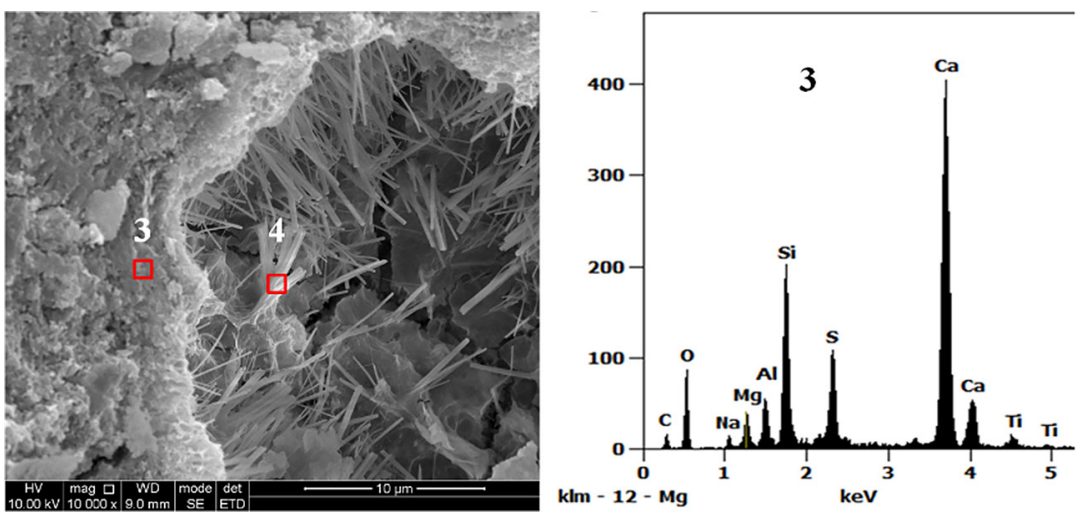

b)
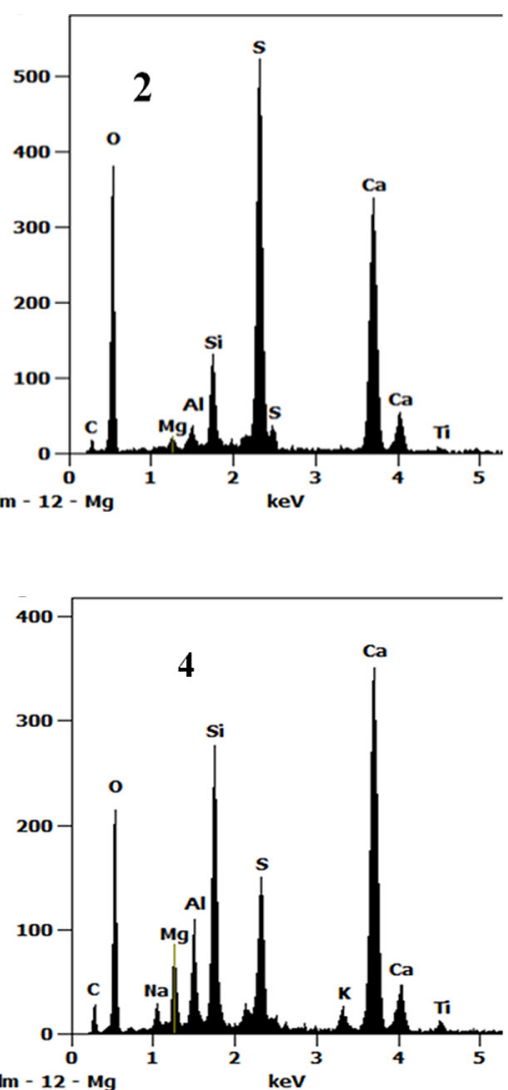

klm - 12 - Mg

Figure 10. Microscopic morphology of the specimens curing up to 7 days.

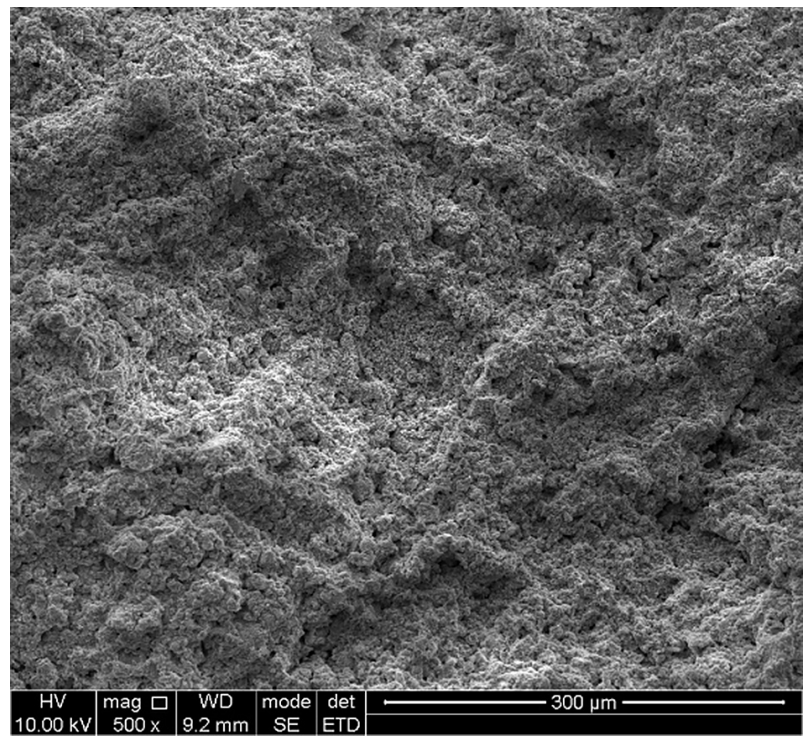

a)

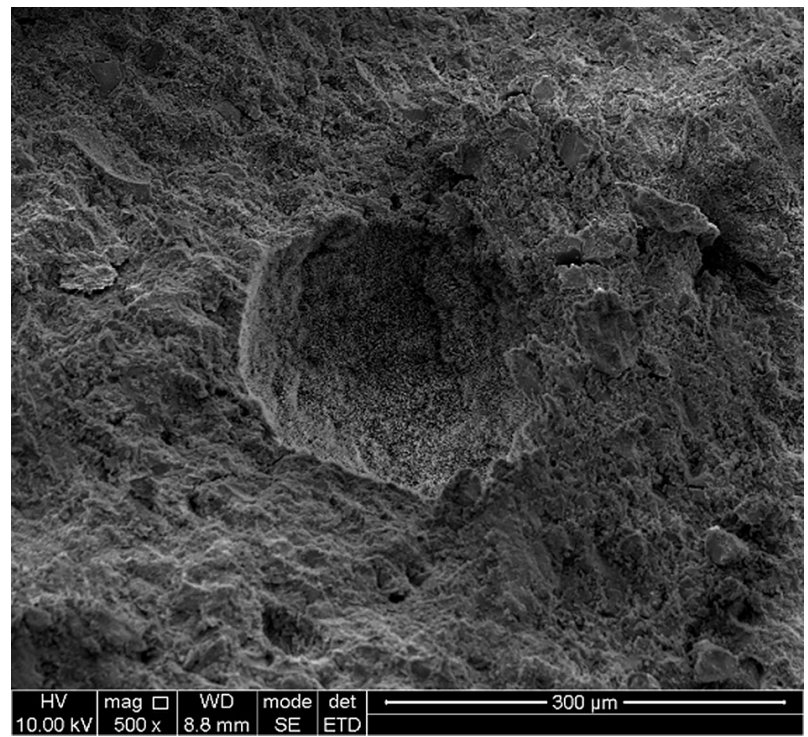

b)

Figure 11. Microscopic morphology of the specimens curing up to 28 days. (Continue on next page) 


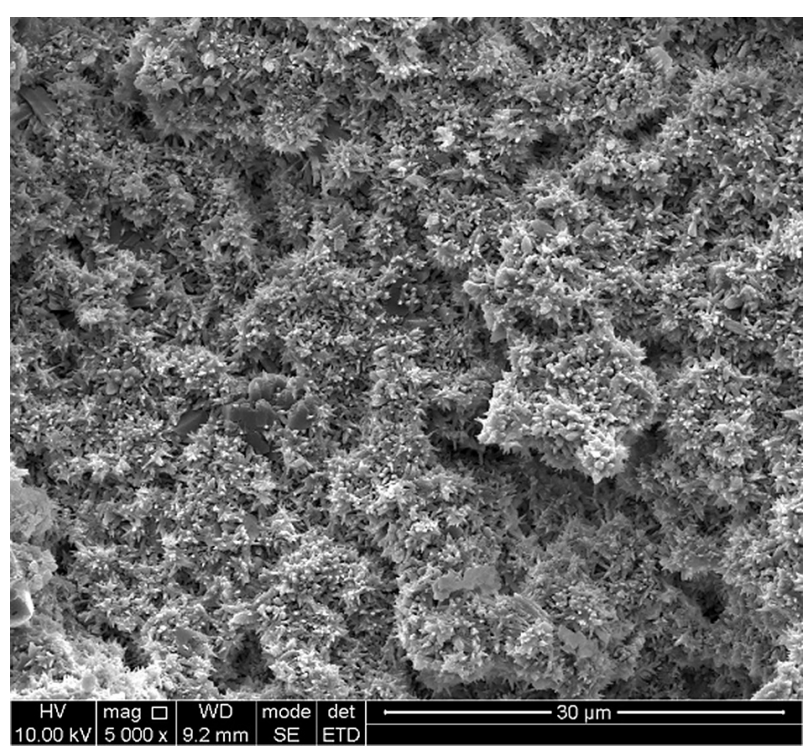

c)

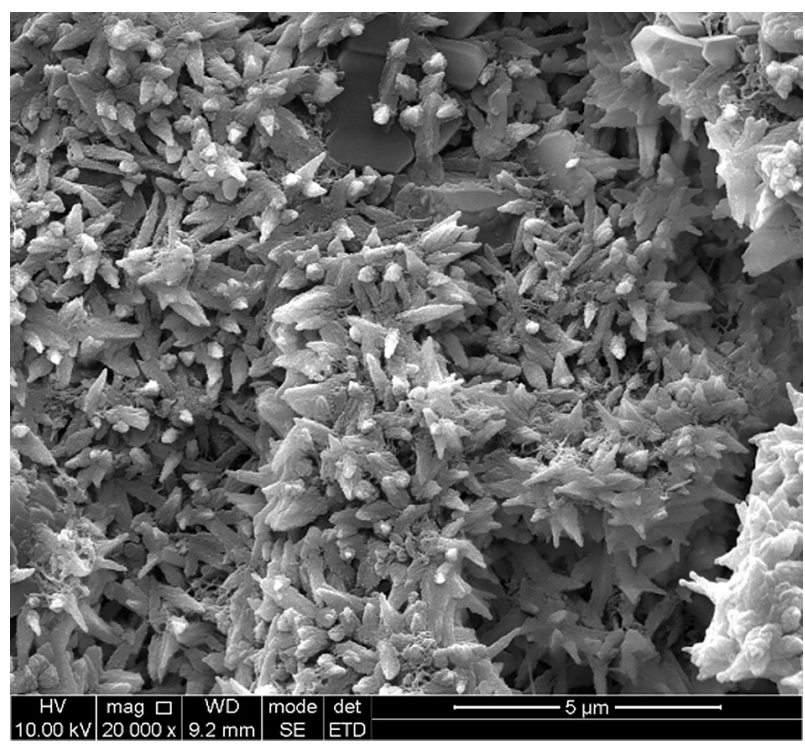

e)

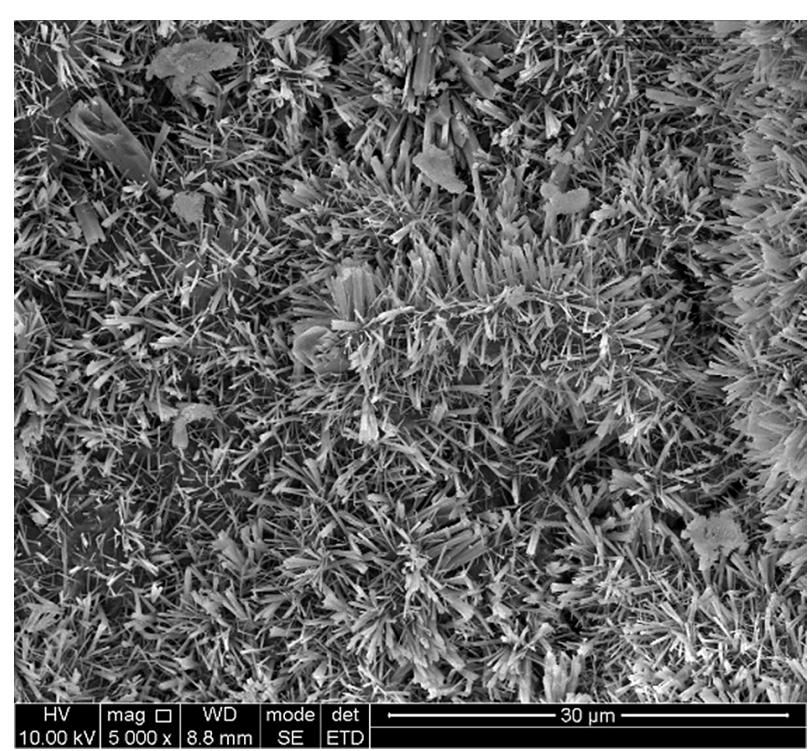

d)

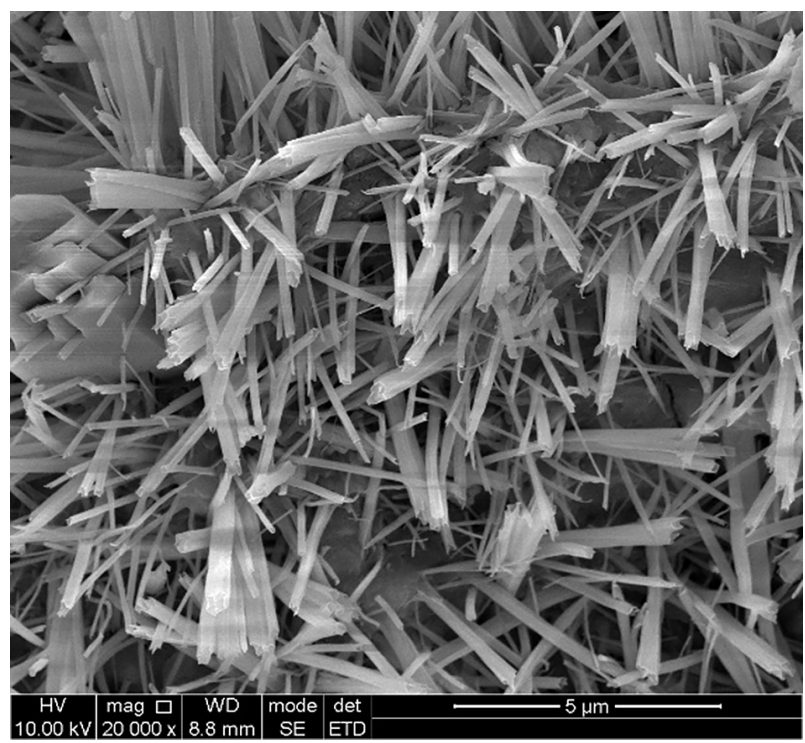

f)

Figure 11. Microscopic morphology of the specimens curing up to 28 days.

specimen on the microscopic scale. The dense structure resulted in SSC2 having a higher strength than the JZ at the early period. This is consistent with the analysis in chapter Mechanical properties. This is due to the calcium hydroxide addition that increased the concentration of $\mathrm{OH}-$ in the system, which accelerates the destruction of the $\mathrm{Ca}-\mathrm{O}, \mathrm{Si}-\mathrm{O}-\mathrm{Si}$ and $\mathrm{Al}-\mathrm{O}-\mathrm{Al}$ bonds in the slag [30, 31]. The generation of the $\mathrm{C}-\mathrm{S}-\mathrm{H}$ gel and $\mathrm{C}-\mathrm{A}-\mathrm{H}$ gel in the hydration reaction was accelerated, which led to the formation of a large amount of ettringite.

The microscopic morphology of the two types of SSC curing up to 28 days was characterised and is pre-sented in Figure 11. The microscopic morphology of the JZ section is mainly a large amount of structurally coated $\mathrm{C}-\mathrm{S}-\mathrm{H}$ gel (Figure 10e). As mentioned above, the products coated by the $\mathrm{C}-\mathrm{S}-\mathrm{H}$ gel are mainly short-rod gypsum and needle-rod ettringite. A large amount of cross-lin-king ettringite (Figure 10f), with a large length to diameter ratio, is present in the cross-sectional morphology of the SSC2. It indicates that the calcium hydroxide addition caused differences in the microstructure and hydration products of the SSC specimens at 28 days. In addition, the difference was not significantly pronounced at 28 days.

\section{CONCLUSION}

In this work, the effects of calcium hydroxide on the microstructure and performance of SSC were investigated, and the hydration products and microstructures of the specimens were characterized by XRD, FTIR and SEM. The main results are as follows: 
- The setting time of super sulfated cement is significantly reduced by calcium hydroxide, while only slightly affecting the fluidity of the cement.

- The mechanical properties of the specimens increased with an increase in the calcium hydroxide content, but the mechanical properties of the specimens decreased after the content exceeded $0.6 \%$.

- The major hydrates of the hardened paste at the early period are mainly $\mathrm{C}-\mathrm{S}-\mathrm{H}$ gel and gypsum in the absence of calcium hydroxide. The addition of calcium hydroxide affects the hydration of the cement, which produces more ettringite and contributes to a denser microstructure of the hardened paste. This is the reason for the higher strength of the SSC with the calcium hydroxide at the early period. Although the control group produces some ettringite at 28 days, the content is not as high as that of the specimens with the calcium hydroxide.

- The microscopic morphology of specimens without the calcium hydroxide is mainly dominated by the interspersed structure of the gypsum and ettringite covered by $\mathrm{C}-\mathrm{S}-\mathrm{H}$. The addition of calcium hydroxide affects the microscopic morphology of the SSC, which mainly consists of an interwoven structure produced by the ettringite and $\mathrm{C}-\mathrm{S}-\mathrm{H}$ gel.

\section{Acknowledgment}

The authors gratefully acknowledge the financial support provided by the National Key Research and Technology Development Program (2019YFC1907200), the State Natural Science Fund project (52078394), Research and Development Project of Ministry of Housing and Urban-Rural Development of the Peoples Republic of China (2019K049), Science and Technology Research and Development Program (CSCEC-2019-Z-24), the CSCEC western construction science and technology research and development Project (ZJXJ-2019-15).

\section{REFERENCES}

1. Liu S., Ouyang J., Ren J. (2020): Mechanism of calcination modification of phosphogypsum and its effect on the hydration properties of phosphogypsum-based supersulfated cement. Construction and Building Materials, 243, 118226. doi: 10.1016/j.conbuildmat.2020.118226

2. Liu S., Fang P., Ren J., et al. (2020): Application of lime neutralised phosphogypsum in supersulfated cement. Journal of Cleaner Production, 272,122660. doi: 10.1016/j.jcle pro. 2020.122660

3. Zhou Y., Peng Z. C., Chen L. C., et al. (2021): The influence of two types of alkali activators on the microstructure and performance of supersulfated cement concrete: mitigating the strength and carbonation resistance. Cement and Concrete Composites, 118, 103947. doi: 10.1016/j.cemconcomp. 2021.103947
4. Gracioli B., Luz C., Beutler C. S., et al. (2020): Influence of the calcination temperature of phosphogypsum on the performance of supersulfated cements. Construction and Building Materials, 262(6),119961. doi: 10.1016/j.conbuildmat. 2020.119961

5. Angulski D. L., D.Hooton R. (2015): Influence of curing temperature on the process of hydration of supersulfated cements at early age. Cement and Concrete Research, 77, 69-75. doi: 10.1016/j.cemconres.2015.07.00

6. Shu W., Jing W., Xiong W., et al. (2016): The use of supersulfated cement (SSC) in mass concrete. MATEC Web of Conferences, 67,07033. doi: 10.1051/matecconf/ 20166707033

7. Gruskovnjak A., Lothenbach B., Winnefeld F., et al. (2008): Hydration mechanisms of super sulphated slag cement. Cement and Concrete Research, 38(7), 983-992. doi: 10. 1016/j.cemconres.2008.03.004

8. Liu S. H., Wang L., Yu B. Y. (2018): The Hydration mechanism of super-sulphate cement and its application. China Concrete, 10, 46-51. (In Chinese) doi: 10.3969/j. issn.1674-7011.2018.10.008

9. Cerulli T., Pistolesi C., Maltese C., et al. (2003): Durability of traditional plasters with respect to blast furnace slagbased plaster]. Cement and Concrete Research, 33(9), 1375-1383. doi: 10.1016/S0008-8846(03)00072-3

10. Grounds T., Nowell D. V., Wilburn F. W. (2003): Resistance of supersulfated cement to strong sulfate solutions. Journal of Thermal Analysis and Calorimetry, 72(1),181-190. doi: 10.1023/A:1023928021602

11. Cabrera-Luna K., Maldonado-Bandala E. E., Nieves-Mendoza D., et al. (2018): Supersulfated binders based on volcanic raw material: Optimization, microstructure and reaction products. Construction and Building Materials, 176, 145-155. doi: 10.1016/j.conbuildmat.2018.05.024

12. Erdem E., Lmez H. (1993): The mechanical properties of supersulphated cement containing phosphogypsum. Cement and Concrete Research, 23(1), 115-121. doi: 10.1016/ 0008-8846(93)90141-U

13. Zhou Y., Hou D., Jiang J., et al. (2018): Experimental and molecular dynamics studies on the transport and adsorption of chloride ions in the nano-pores of calcium silicate phase: the influence of calcium to silicate ratios, Microporous and Mesoporous Materials, 255, 23-35. doi: 10.1016/j.micro meso.2017.07.024

14. Chen B., Horgnies M., Huet B., et al. (2020): Comparative kinetics study on carbonation of ettringite and meta-ettringite based materials. Cement and Concrete Research, 137, 106209. doi: 10.1016/j.cemconres.2020.106209

15. Kaufmann J., Winnefeld F. (2019): Seasonal heat storage in calcium sulfoaluminate based hardened cement pas-tesexperiences with different prototypes. Journal of Energy Storage, 25, 100850.1-100850.12. doi: 10.1016/j.est.2019. 100850

16. Kondo R., Chong T. S., Goto S., et al. (1979): The latent hydraulic property of granulated blast furnace slag by various activators. Tetsu-to-Hagane, 65(13), 1825-1829. doi: 10.2355/tetsutohagane1955.65.13_1825

17. Masoudi R., Hooton R. D. (2019): Examining the hydration mechanism of supersulfated cements made with high and low-alumina slags. Cement and Concrete Composites, 103, 193-203. doi: 10.1016/j.cemconcomp.2019.05.001

18. Castellote M., Andrade C., Turrillas X., et al. (2008): Accelerated carbonation of cement pastes in situ monitored 
by neutron diffraction. Cement and Concrete Research, 38(12), 1365-1373. doi: 10.1016/j.cemconres.2008.07.002

19. Pinto S.R., da Luz C.A., Munhoz, G.S., et al. (2020) Resistance of phosphogypsum-based supersulfated cement to carbonation and chloride ingress. Construction and Building Materials, 263, 120640. doi: 10.1016/j.conbuildmat. 2020. 120640

20. Gijbels K., Pontikes Y., Samyn P., et al. (2020): Effect of $\mathrm{NaOH}$ content on hydration, mineralogy, porosity and strength in alkali/sulfate-activated binders from ground granulated blast furnace slag and phosphogypsum. Cement and Concrete Research, 132, 106054. doi: 10.1016/j.cem conres.2020.106054

21. Lei J. W., Lan W. W., Yang E.H. (2021): Effect of calcium hydroxide on the alkali-silica reaction of alkali-activated slag mortars activated by sodium hydroxide. Construction and Building Materials, 272, 121868. doi: 10.1016/j.con buildmat.2020.121868

22. He T. S., Li B., Zhao S. Y., et al. (2021): Study on the particle morphology, powder characteristics and hydration activity of blast furnace slag prepared by different grinding methods. Construction and Building Materials, 270, 121445. doi: 10.1016/j.conbuildmat.2020.121445

23. Sun D. W., Wang Y. L., Ma W. X., et al. (2021): C-S-H gel structure and water molecules behaviors under different chemical environments in a range of temperatures. Materials Today Communications, 26, 101866. doi: 10.1016/j. mtcomm.2020.101866

24. Liu S. H., Quyang J. Y., Ren J. (2020): Mechanism of calcination modification of phosphogypsum and its effect on the hydration properties of phosphogypsum-based su- persulfated cement. Construction and Building Materials, 243, 118226. doi: 10.1016/j.conbuildmat.2020.118226

25. Yu B. Y., Gao Y. X., Wang J. (2014): Hydration behavior of super sulphated cement with different types of gypsum. Journal of Building Materials, 17(06), 965-971. (In Chinese) doi: 10.3969/j.issn.1007-9629.2014.06.005

26. Xiao J. M., Li H., Zhu H. M., et al. (2018): Analysis on hydration products of cement-slag complex binder pastes by FTIR and NMR. Journal of Materials Science and Engineering, 36(04), 132-137 (In Chinese). doi: 10.14136/j. cnki.issn1673-2812.2018.04.025

27. Fu B, Cheng Z. Y., He Y. T., et al. (2020): Effect of slag on thaumasite sulfate attack resistance of cement paste. Bulletin of the Chinese Ceramic Society, 39(02), 141-146. doi: 10.16552/j.cnki.issn1001-1625.20200226.001

28. Chai Q. (2015). Studies on mechanical performance and durability of alkali-salt compound activated bottom ashbased geopolymer. Xi'an University of Architecture and Technology (In Chinese).

29. Zhang J S. (2017). Study on the regulation of ettringite morphology and its mechanism. China Building Materials Academy (In Chinese).

30. Collier N. C., Li X., Bai Y., et al. (2015): The effect of sulfate activation on the early age hydration of BFS: PC composite cement. Journal of Nuclear Materials, 464, 128-134. doi: 10.1016/j.jnucmat.2015.04.044

31. Min P. H., Park S., Shon I. J., et al. (2021): Influence of Portland cement and alkali-activated slag binder on the thermoelectric properties of the p-type composites with MWCNT. Construction and Building Materials, 292, 123601. doi: 10.1016/j.conbuildmat.2021.123393 